\title{
Ranking important factors on information technology in development free zone markets: An AHP implementation
}

\author{
Naser Azad ${ }^{\mathrm{a}^{*}}$, and Yahya Rostamnya
}

${ }^{a}$ Department of Management, Islamic Azad University, South Tehran Branch, Tehran, Iran ${ }^{b}$ Department of Management, PayamNoorUniversity, Rey city, Iran

AR T I C LE I N F O AB T R A T

Article history:

Received October 1, 2011

Received in Revised form

November, 14, 2011

Accepted 30 January 2012

Available online

15 February 2012

Keywords:

Information technology

Marketing planning

AHP

Multiple criteria decision making

\begin{abstract}
Information technology (IT) plays a vital role on developing different markets. In this paper, we study the impact of IT on developing businesses located mainly on free zones or in the borders of countries using analytical hierarchy process. The proposed study of this paper gathered the relative importance of five important factors influencing IT implementation. There are 12 experts and we use pairwise comparison to gather their insight and using Expert Choice we implement AHP for ranking the factors. The results indicate that management is the most important factor, followed by cultural and social items. The other factors including technical, investment and organization items are in lower degree of importance.
\end{abstract}

\section{Introduction}

Information technology has become an inevitable fact to reach a successful business model in today's economy. During the past few years, there have been many studies associated with measuring the effects of IT based infrastructure on developing economy (Lu et al., 2009; Darrat \& Saifs, 2010). Wang and Shi (2011), for instance, performed an investigation on understanding ICT adoption in the small firm sector in Southern Africa. Zhou (2011) evaluated critical success factors of mobile website adoption. Al-Mabrouk and Soar (2009) presented a study based on Delphi method for emerging issues for successful information technology transfer in North Africa a case of Libya.

Information technology (IT) plays an important role on developing different markets. Today, people can easily purchase goods from different stores using different IT services such as POS, ATM, etc. These devices help customers literally make financial transactions very easily. Azad and Rostamnya (2012) studied the impact of IT on developing businesses located mainly on free zones or in the * Corresponding author.

E-mail addresses: dr.naserazad@yahoo.com (N. Azad) 
borders of countries. They distributed 300 questionnaires consists of 35 questions among different people and build structural equations using 28 variables. They analyzed the results using LISREL software package and grouped the items in five different groups including management, social and cultural, organizational, technical and investment factors and the statistical tests indicated that all factors could influence IT development, significantly.

Hosseini et al. (2009) investigated a survey to identify the challenges in application of information and communication technology (ICT) by extension service in Iran. They designed a questionnaire and collected data from 187 extension specialists. The ordinal factor analysis was incorporated and the results indicated the classification of the challenges into six latent variables. The variables were classified in organizational, technical, social, financial, regulatory and human factors. Nakhai Kamalabadi et al. (2008) identified the vital challenges and barrier of e-commerce implementation in Iran. They ranked the challenges to find the most important challenges among them. They also suggested different courses of actions to remove the barriers and challenges using AHP method for ranking them. Peyala (2011) studied the impact of using information technology in central university libraries in India. Peyala found that information technology had a significant impact on the efficiency of library operations and the delivery of information services. Peyala also reported that the use of IT had facilitated networking and resource sharing, removed duplication of effort, speeded up of operations, increased access to information resources and improved the quality of information services.

Vinay and Sharma (2010) argued based on the literature on management information system (MIS) that the success of IT implementation in various strategic organization depends on the different critical success factors (CSFs) of MIS implementation. They developed a conceptual framework by setting a linkage between organizational strategy and CSF of information system implementation in terms of three propositions and analyzed the data to verify the conceptual framework. Zandi and Tavana (2011) presented a fuzzy goal programming model for strategic information technology investment assessment. They proposed a novel two-dimensional method, which determines the deferrable strategy with the most value by maximizing the real option values while minimizing the risks associated with each alternative strategy. They reported that managers could face the difficulty that most IT investment projects incorporate high level of risk, especially in a rapidly changing business environment. Their proposed model presented a framework used to evaluate IT investments based on the real option concept. The method consists of intuitive, generic and comprehensive technique, which incorporates the linkage among economic value, real option value and IT investments, which could lead to a better-structured decision process.

Zhou (2011) examined the critical success factors of mobile web site adoption. His results indicated that system quality was the main factor affecting perceived ease of use, whereas information quality was the primary factor influencing perceived usefulness. Service quality also impacted on trust and perceived ease of use and perceived usefulness, perceived ease of use and trust determined user satisfaction. Dale Stole and Muhanna (2009) proposed a contingency perspective and explained that IT capabilities' influencing on firm resources was contingent on the "fit" between the type of IT capability/resource and the demands of the industry in which it competes. In other works, using publicly available rankings as proxies for two kinds of internally and externally focused IT capabilities, they empirically studied the degree in which three industry characteristics of dynamism, munificence, and complexity influenced on measures of financial performance. They reported that there was a general support for the posited contingency model.

Nasir and Sahibuddin (2011) performed an empirical study to detect the critical success factors for software projects. They used the content analysis and frequency analysis and detected twenty-six critical success factors associated with the software project success. They recommended that firms or project manager could control the top five critical factors to drive towards project success. Based on 
their findings, it seems that non-technical factors (94\%) dominated over technical factors (6\%). In a result unique to our study compared with previous one, they reported that the items of clear and frozen requirements, realistic estimation of the schedule and budget, along with a competent project manager were the five most critical success factors of software projects. Soto-Acosta et al. (2010) collected a large data source by the European e-Business Market Watch and reported that web infrastructure was not substantially associated with business value. However, Internet-based innovation provided significantly a positive influence on business value. They believed there was no significant complementarities between web infrastructure and internet-based innovation. The results indicated that companies should be careful when they decide to make this kind of investments, since they have to invest heavily in web infrastructure with 'soft' investments for the development of new services, products and processes exploiting the capabilities of this infrastructure.

Omar et al. (2010) investigated the level of information sharing, information quality and usage of IT based tools among manufacturing firms located in the Northern region of Malaysia by gathering data through distributing questionnaires among some managers. The results revealed that manufacturing firms recognized the importance of information sharing, information quality and IT tools framwork in the context of supply chain management. While the usage of IT tools was reported to be between moderate to high, the overall results provided some insights into the types of data shared between manufacturers and suppliers. Bhatt and Emdad (2010) presented an empirical study of the relationship between IT infrastructure, customer focus, and business advantages. They reported IT infrastructure to have a substantial impact on customer responsiveness, but it did not present any substantial impact on product/service innovation. IT infrastructure, customer responsiveness, and product/service innovation were reported to be relatively associated with business advantages.

The proposed study of this paper performs an empirical study to examine the relationship between IT and the success of business units located in regional and borders of country. The proposed study first presents the framework of survey in section 2 and details of our findings are given in section 3 . The paper ends with concluding remarks to summarize the contribution of this paper.

\section{The proposed framework}

The proposed study of this paper studies the impact of five important IT factors, M1, including management (M2), social and cultural (M3), organizational (M4), technical (M5) and investment (M6) on the success of business models located in the borders of country where people may intend to travel between two countries.

Management factor (M2) includes four variables, which are bad management (V2), effective style of management (V27), middle stage management resistance (V5) and top management (V27). Social and cultural factor consists of six factors including low level awareness of the users from the advances of IT (V9), Acceptance of IT on behalf of users (V18), Competition (V13), employee resistance (V24), organization culture (V17) and training of employees (V25).

Organizational factor (M4) has five factors including the existence of a unique team-work (V20), the lack of IT specialist (V35), the organizational structure (V4), the role of government (V14) and the lack of sufficient infrastructure (V23). Technical factors (M5) includes seven items including the lack of IT supervision (V3), the low speed of internet connection (V29), the lack of sufficient band wide (V30), the lack of necessary hardware equipments (V6), the lack of sufficient software packages (V7), the lack of user friendly of equipments (V3) and the complexity of IT (V28). Finally, the last factor, Investment (M6), consists of six factors including the lack of investment on behalf of private and public sector on IT infrastructure (V8), the size of organization (V16), the access on financial and technical facilities (V15), the high amount of investment required (V33) and the bad experience of low return of previous investment plans on IT (V1). 
As we can observe, there are 5 main criteria and 28 sub-criteria associated with the proposed study of this paper and we intend to use 12 experts for pairwise comparisons. The results are analyzed using analytical hierarchy process (AHP) and details of the computations are accomplished using Expert choice software package.

\section{Results}

Table 1 shows details of the pairwise comparison for the main factors of the implementation information technology.

\section{Table 1}

Pairwise comparison of the main factors

\begin{tabular}{lccccc}
\hline Factor & Management & Cultural and Social & Organizational & Technical & Investment \\
\hline Weight & 0.38 & 0.215 & 0.076 & 0.177 & 0.152 \\
Rank & 1 & 2 & 5 & 3 & 4 \\
\hline
\end{tabular}

As we can observe from the results of Table 1, management is the most important factor, followed by cultural and social items. The other factors including technical, investment and organization items are in lower degree of importance.

\subsection{Management}

The first item, which is management consists of four items including bad management (V2), effective style of management (V27), middle stage management resistance (V5) and top management (V27). Table 2 shows details of our pairwise comparison.

Table 2

Pairwise comparison of the factors associated with management

\begin{tabular}{lcccc}
\hline Factor & Bad management & Style of management & Middle stage management resistance & Top management \\
\hline Weight & 0.069 & 0.525 & 0.302 & 0.103 \\
Rank & 4 & 1 & 2 & 3 \\
\hline
\end{tabular}

According to the results of Table 2, management style plays an important role followed by middle stage management resistance. The other factors of top management support and bad management are in lower priorities.

\subsection{Cultural and Social factor}

Social and cultural factor consists of six factors including low level awareness of the users from the advances of IT (V9), Acceptance of IT on behalf of users (V18), Competition (V13), employee resistance (V24), organization culture (V17) and training of employees (V25). Table 3 shows details of our pairwise comparisons.

Table 3

Pairwise comparison of the factors associated with cultural and social factors

\begin{tabular}{llcc}
\hline & Title & Weight & Rank \\
\hline 1 & Low level awareness of the users from the advances of IT & 0.072 & 5 \\
2 & Acceptance of IT on behalf of users & 0.178 & 3 \\
3 & Competition among different rivals & 0.058 & 6 \\
4 & Employee resistance & 0.249 & 2 \\
5 & Organization culture & 0.114 & 4 \\
6 & Training of employees & 0.329 & 1 \\
\hline
\end{tabular}


As we can observe from the results of Table 2, the lack of a good training of employees is the most important factor, which could be considered as the main barrier for the success of IT implementation. Employee resistance is the second important factor preventing IT implementation and general acceptance of IT on behalf of users is the third important factor. The other important factors are organizational culture, low level awareness of users from the advances of IT and competition among different rivals are other important factors.

\subsection{Organizational factors}

Organizational factor (M4) includes five items including the existence of a unique team-work with the relative importance of 0.454 , which is the first important item. Organizational cultural is the second factor with the relative importance ratio of 0.229 and the lack of sufficient infrastructure is the third item with the relative importance of 0.149 . Government comes in the next priority with the relative importance of 0.101 and lack of IT specialist with the relative importance of 0.067 is the last important item.

\subsection{Technical factors}

There are seven items associated with technical factors and the most important one was unavailability of the necessary software packages with the weight of 0.301 . The second important factor is the low speed of internet with the relative weight of 0.286 . The third item is lack of the necessary hard equipment with the relative importance of 0.147 . The existing complexity of technology with the relative importance of 0.147 is the fourth important factor. The fifth item is the easy access of the software packages with the relative importance of 0.068 and the last items are the insufficient band wide, 0.045 , and insufficient supervision with 0.037 .

\subsection{Investment factors}

Investment factors consist of six items where the lack of investment on behalf of private sector is the most important one with the relative importance of 0.334 , followed by high investment required with the relative importance of 0.269 . Security is the third important factor with the relative importance of 0.184. The other factors, which are of lower degree of importance are the size of organization, low return of investment and technical issues.

\section{Conclusion}

In this paper, we have presented an empirical study measure the impact of five factors on successful IT implementation on the borders of country. The proposed study of this paper used analytical hierarchy process to rank important factors influencing the implementation of IT. The results of this study indicated that management was the most important factor, followed by cultural and social items. The other factors including technical, investment and organization items are in lower degree of importance.

\section{Acknowledgment}

The authors would like to acknowledge Islamic Azad University for their support on this work. We also appreciate the comments received by referees on earlier version of this work.

\section{References}

Azad, N, \& Rostamnya, Y. (2012). The role of information technology on developing free zone markets. Management Science Letter, 2(3), 1017-1022. 
Al-Mabrouk, K., \& Soar, J. (2009). A Delphi examination of emerging issues for successful information technology transfer in North Africa a case of Libya. African Journal of Business Management 3, 107-114.

Bhatt, G. D. \& Emdad, A. F. (2010). An empirical examination of the relationship between information technology (IT) infrastructure, customer focus, and business advantages. Journal of Systems and Information Technology, 12(1), 4-16.

Cronbach, L. J. (1951). Coefficient alpha and the internal structure of tests. Psychometrika, 16(3), 297-334.

Darrat, A. \& Saifs, A. (2010). Information technology, financial deepening and economic growth: Some evidence from a fast growing emerging economy. Journal of Economics and International Finance, 2(2), 28-35.

Dale Stole, M., \& Muhanna, W.A. (2009). IT capabilities and firm performance: A contingency analysis of the role of industry and IT capability type. Information \& Management, 46(3), 181189.

Dong QI, J. (2011). User acceptance of information technology innovations in the remote areas of china. Journal of Knowledge-based Innovation in China, 3(1), 44-53.

Harjeev K. Khanna, D.D. Sharma, \& Laroiya, S.C. (2011). Identifying and ranking critical success factors for implementation of total quality management in the Indian manufacturing industry using TOPSIS. Asian Journal on Quality, 12(1), 124-138.

Hossini, S. J., Niknami, M., \& Chizari, M. (2009). To determine the challenge in the application of ICTs by the agricultural extension service in Iran. Journal of Agricultural Extension and Rural Development, 1, 27-30.

Likert, R. (1932). A Technique for the Measurement of Attitudes. Archives of Psychology, 140, 1-55.

Lu, Y., Zhou, T., \& Wang, B. (2009). Exploring Chinese user acceptance of instant messaging using the theory of planned behavior, the technology acceptance model and the flow theory. Journal of Computer in Human Behavior, 25, 29-39.

Mohanna, Sh., Yaghoubi, N.M., Vahidi Motlaq, S., \& Vahidi Motlaq,T. (2011). Limitation of ecommerce implementation in developing countries, case study of Iran. American Journal of Scientific and industrial Research, 2(2), 214-228.

Nakhai Kamalabadi, I., Bayat, A., Ahmadi, P., \& Ebrahimi, A. (2008). Identifying and prioritization of challenges and barriers of e-commerce implementation in Iran. World Applied Science Journal, 5(5), 590-597.

Nasir, M.H.N., \& Sahibuddin, S. (2011). Critical success factors for software projects: A comparative study. Scientific Research and Essays, 6(10), 2174-2186.

Omar, R., Ramayah, T., Lo, M.C., Sang, T.Y. \& Siron, R. (2010). Information sharing, information quality and usage of information technology (IT) tools in Malaysian organizations. African Journal of Business Management. 4(12), 2486-2499.

Peyala, V. (2011) Impact of using information technology in central university libraries in India: Results of a survey. Program: Electronic Library and Information Systems, 45(3), 308 - 322.

Soto-Acosta, P., Loukis, E., Colomo-Palacios, R., \& Lytras, M.D. (2010). An empirical research of the effect of internet-based innovation on business value. African Journal of Business Management, 4(18), 4096-4105.

Vinay, S., \& Sharma, R.R.K. (2010). Relating critical success factors of information implementation with organizational strategy. International Journal of Business Strategy Publisher, 10(2).

Wang, Y., \& Shi, X. (2011). Understanding ICT adoption in the small firm sector in Southern Africa. Journal of Systems and Information Technology, 13(2), 179-199.

Zandi, F., \& Tavana, M. (2011). A fuzzy goal programming model for strategic information technology investment assessment. Benchmarketing: An International Journal, 18(2),172-196.

Zhou, T. (2011). Examining the critical success factors of mobile website adoption. Online Information Review, 35(4), 636-652. 